The Texas Medical Center Library

DigitalCommons@TMC

The University of Texas MD Anderson Cancer Center UTHealth Graduate School of Biomedical Sciences Dissertations and Theses (Open Access)
The University of Texas MD Anderson Cancer

Center UTHealth Graduate School of

Biomedical Sciences

$5-2018$

\title{
GENETIC TESTING PRACTICES OF GENETIC COUNSELORS, GENETICISTS, AND PEDIATRIC NEUROLOGISTS WITH REGARD TO CHILDHOOD-ONSET NEUROGENETIC CONDITIONS
}

Sara Wofford

Follow this and additional works at: https://digitalcommons.library.tmc.edu/utgsbs_dissertations

Part of the Genetics Commons, Medical Education Commons, Neurology Commons, Other Genetics and Genomics Commons, Other Neuroscience and Neurobiology Commons, and the Pediatrics Commons

Recommended Citation

Wofford, Sara, "GENETIC TESTING PRACTICES OF GENETIC COUNSELORS, GENETICISTS, AND PEDIATRIC NEUROLOGISTS WITH REGARD TO CHILDHOOD-ONSET NEUROGENETIC CONDITIONS" (2018). The University of Texas MD Anderson Cancer Center UTHealth Graduate School of Biomedical Sciences Dissertations and Theses (Open Access). 865.

https://digitalcommons.library.tmc.edu/utgsbs_dissertations/865

This Thesis (MS) is brought to you for free and open access by the The University of Texas MD Anderson Cancer Center UTHealth Graduate School of Biomedical Sciences at DigitalCommons@TMC. It has been accepted for inclusion in The University of Texas MD Anderson Cancer Center UTHealth Graduate School of Biomedical Sciences Dissertations and Theses (Open Access) by an authorized administrator of DigitalCommons@TMC. For more information, please contact digitalcommons@library.tmc.edu.

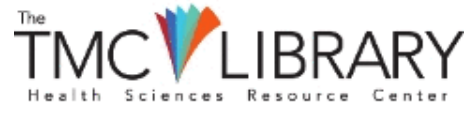


GENETIC TESTING PRACTICES OF GENETIC COUNSELORS, GENETICISTS, AND PEDIATRIC NEUROLOGISTS WITH REGARD TO CHILDHOOD-ONSET NEUROGENETIC CONDITIONS

by

Sara Christine Wofford, B.S.

APPROVED:

Sarah Noblin, M.S., CGC

Advisory Professor

Victoria Wagner, M.S., CGC

Jessica Davis, M.S., CGC

Laura Farach, M.D.

Pedro Mancias, M.D.

Syed Hashmi, M.D., M.P.H., Ph.D.

APPROVED:

Dean, The University of Texas

MD Anderson Cancer Center UTHealth Graduate School of Biomedical Sciences 
GENETIC TESTING PRACTICES OF GENETIC COUNSELORS, GENETICISTS, AND PEDIATRIC NEUROLOGISTS WITH REGARD TO CHILDHOOD-ONSET NEUROGENETIC CONDITIONS

\author{
A THESIS \\ Presented to the Faculty of \\ The University of Texas \\ MD Anderson Cancer Center UTHealth \\ Graduate School of Biomedical Sciences \\ in Partial Fulfillment \\ of the Requirements \\ for the Degree of \\ MASTER OF SCIENCE
}

by

Sara Christine Wofford, B.S.

Houston, Texas

May, 2018 
GENETIC TESTING PRACTICES OF GENETIC COUNSELORS, GENETICISTS, AND PEDIATRIC NEUROLOGISTS WITH REGARD TO CHILDHOOD-ONSET NEUROGENETIC CONDITIONS

\author{
Sara Christine Wofford, B.S.
}

Advisory Professor: Sarah Noblin, M.S., CGC

Identifying genetic diagnoses for neurological conditions with a considerable hereditary component, such as autism spectrum disorder (ASD), intellectual disability, and epilepsy, is critical to providing proper medical management for these patients and their families. However, many patients with these conditions are not tested appropriately or receive no genetic testing at all (1). The current study was designed to characterize the genetic testing practices of the providers most likely to evaluate or order genetic testing for these patients: pediatric neurologists, geneticists, and genetic counselors. The study noted significant variance between the testing strategies selected by pediatric neurologists compared to those of geneticists and genetic counselors and supports the need for updated guidelines that are consistent across specialties. Pediatric neurologists report lower confidence with ordering genetic testing and a need and desire for further education regarding genetic testing. This study proposes that the continued integration of genetic counselors into pediatric neurology clinics may improve utilization of genetic testing while reducing the burden on neurologists. 


\section{Table of Contents}

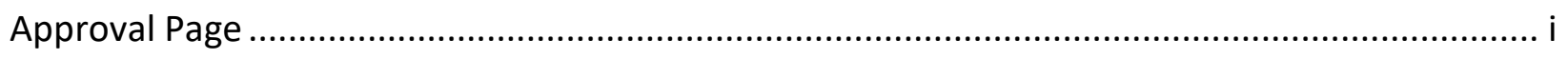

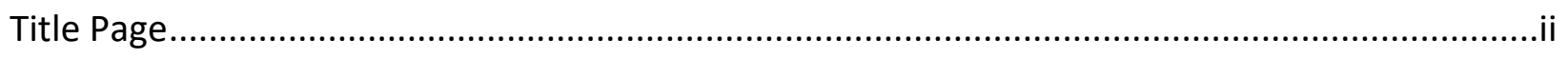

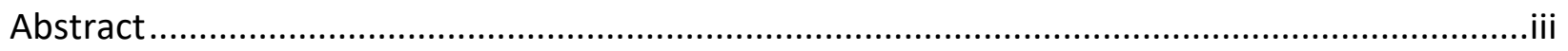

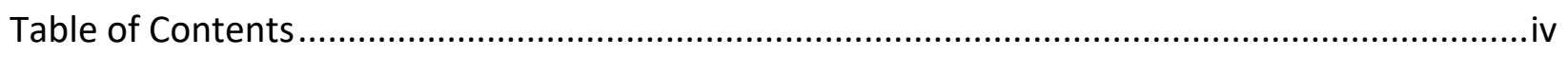

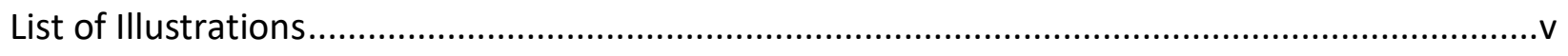

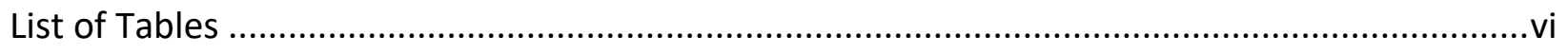

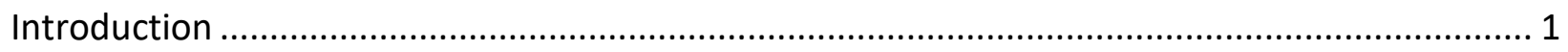

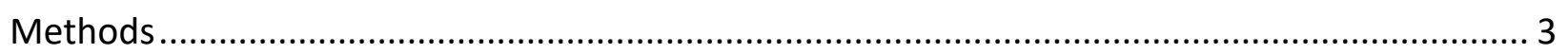

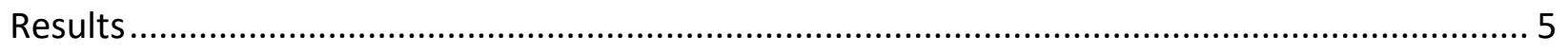

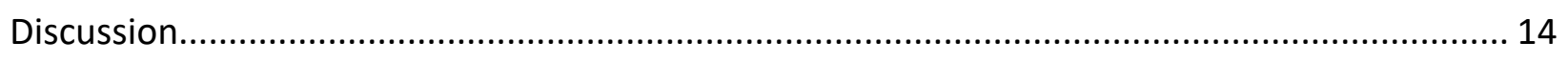

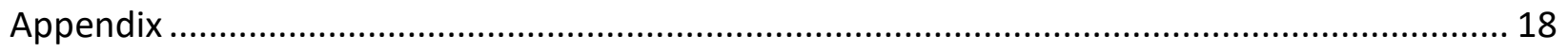

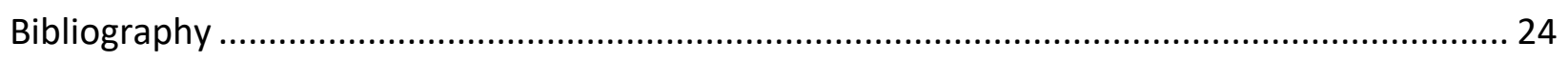

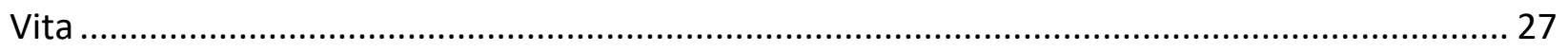




\section{List of Illustrations}

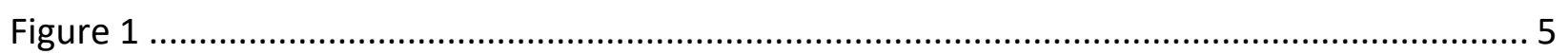




\section{List of Tables}

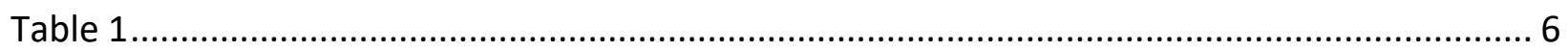

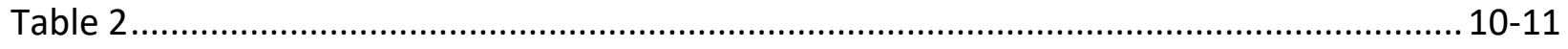

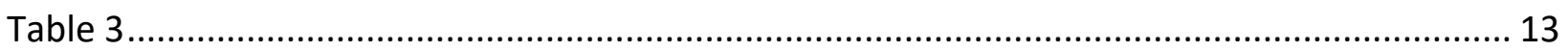




\section{Introduction}

Many neurological conditions identified in childhood, such as autism spectrum disorder (ASD), epilepsy, and intellectual disability have a significant genetic component. Approximately $1 \%$ of children living in the United States have ASD and $10 \%$ of those cases are due to an underlying genetic disorder, such as Fragile X syndrome (FXS) (2-5). Similarly, approximately $1 \%$ of the United States population has epilepsy and up to $3 \%$ of individuals with epilepsy have a genetic form $(6,7)$. Intellectual disability is found in approximately $1-3 \%$ of individuals, and, depending on the severity of the delay, $25-50 \%$ of those cases are related to a genetic abnormality(8). Given the significant chance of identifying a genetic etiology in many common childhood-onset neurological conditions, genetic testing offers considerable value to patients with these disorders, not only for diagnostic purposes, but also to determine if other specialty evaluations and treatments are indicated or if additional family members may have health or reproductive implications. For example, patients with ASD related to FXS should be screened for cardiac abnormalities and their family members may require evaluation for FXS or related health concerns. These recommendations differ greatly from those typically made for children with non-syndromic ASD (9).Therefore, children with ASD who do not receive testing for FXS may be missing necessary medical treatments and evaluations.

Proper utilization of genetic testing involves not only patients receiving testing when indicated, but also the selection of the best testing strategy for a particular indication. Unfortunately, previous literature suggests many individuals with neurological conditions that warrant genetic testing do not receive recommended testing (1). Approximately $68 \%$ of 
children with ASD do not receive any genetic testing despite current recommendations (1). For patients with ASD, the 2013 ACMG guidelines recommend chromosomal microarray (CMA) and FXS analysis. However, the most recent Child Neurology Society Guidelines for the screening and diagnosis of ASD recommends karyotyping and FXS analysis $(10,11)$. Notably, CMA was not used in clinical practice in 2000 , the time of this publication. A similar pattern is seen for patients with unexplained intellectual disability. The American Academy of Pediatrics (AAP), American Academy of Neurology and American College of Medical Genetics and Genomics (ACMG) recommend CMA and FXS analysis as first-tier testing (12-14). By contrast, the relevant Child Neurology Society Guidelines from 2000, last updated in 2010, recommend karyotype analysis in addition to FXS analysis. Currently, there are no professional guidelines outlining proper genetic testing practices for patients with epilepsy. The variation in recommendations across specialties for these neurological conditions may present an obstacle to patients receiving recommended testing and appropriate medical care.

In order to address the issue of proper utilization of genetic testing for patients with neurological conditions, it is necessary to gather data about the genetic testing practices of the practitioners that most commonly participate in ordering their genetic testing. The purpose of this study was to compare the attitudes and practices of pediatric neurologists, medical geneticists, and genetic counselors regarding genetic testing for pediatric patients with neurological conditions. Through doing so, this study aimed to identify where these providers differ in their utilization of genetic testing with the goal of informing plans to increase consistent and appropriate utilization of genetic testing for this patient population. 


\section{Methods}

Study Design

This was a cross-sectional study utilizing an electronic survey to assess the genetic testing practices of genetic counselors, geneticists, and pediatric neurologists. Approval of this study was granted by the Institutional Review Board at The University of Texas MD Anderson Cancer Center UTHealth Graduate School of Biomedical Sciences (IRB Number: HSC-GSBS-170695).

Genetic counselors, medical geneticists, and pediatric neurologists that are boardcertified in their field, see patients with neurological conditions at least once per month, and have ordered genetic testing within the last six months met the inclusion criteria for this study. Participants were contacted electronically, either personally or through the listserv of their respective professional organization. Genetic counselors were recruited from the National Society of Genetic Counselors via an initial electronic mail message and a follow up reminder three weeks later; while pediatric neurologists were contacted via the Child Neurology Society (CNS) listserv through a single electronic mail message. Medical geneticists were contacted by two personal electronic mail messages informing them of the option to participate in this study. Responses were collected over a period of approximately three months between September 22, 2017 and December 10, 2017.

\section{Instrumentation}

The instrumentation used in this study was an investigator-designed, non-validated questionnaire hosted on Qualtrics ${ }^{\circledR}$, an online survey software. All participants took the survey 
online and their responses remained anonymous. Participants had the option to participate in a random drawing for one of two available gift cards by providing contact information that was not linked to the individual's survey responses.

The survey was divided into five sections: assessment of genetic testing utilization (11 items), scoring of factors considered when deciding on a genetic testing strategy (4 items), assessment of testing practice for common indications (4 items), self-reported knowledge assessment of genetics topics ( 4 items), and demographic information (5 items). It was optional to answer each question. Question types included single choice, visual analog scale (VAS), and Likert scales (see appendix 1). The survey instrument was created specifically for this project and was reviewed for clarity and consistency by the authors. The instrument was not validated.

\section{Data Analysis}

Data from Qualtrics was imported in STATA (v.13.0, College Station, TX) for analysis. Categorical variables are described using frequencies and percentages. Continuous variables were not normally distributed and are described using medians and interquartile ranges (IQR). Comparison between clinician groups were made using contingency tests (chi-square or Fisher exact) for categorical variables and using Kruskal-Wallis test with a post-hoc Dunn's test for continuous variables. Comparison of data between groups was evaluated using descriptive analysis. Statistical significance was assumed at a Type I error rate of $5 \%$. 


\section{Results}

Respondent Demographics

Of the 397 individuals who opened the survey, 251 submitted a completed survey and met the inclusion criteria. Those responses included 103 genetic counselors, 35 geneticists, and 113 pediatric neurologists (Figure 1 ).

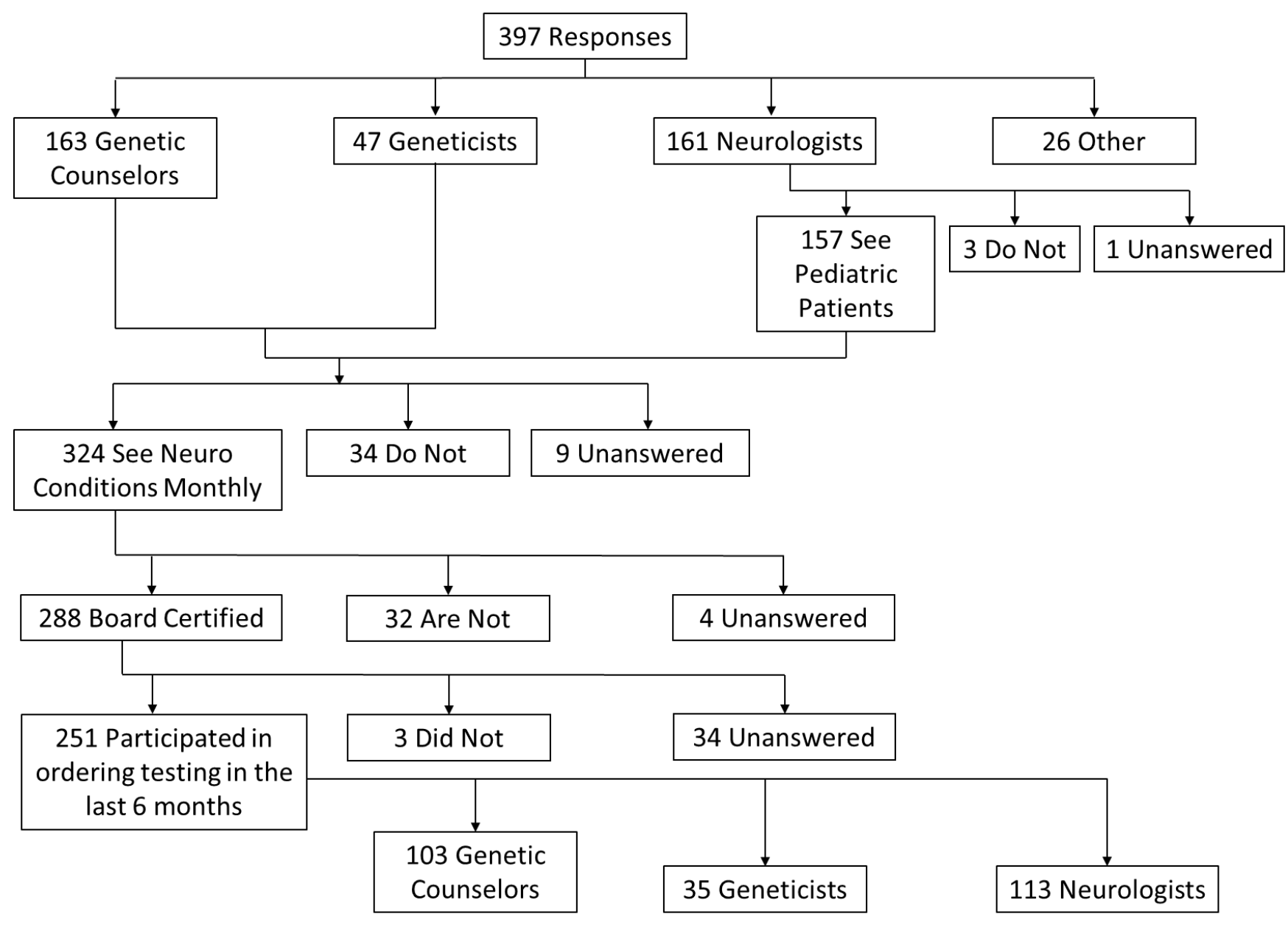

Figure 1:Responses flowchart describing inclusion and exclusion criteria

Of the 251 respondents, 51\% reported working in their field for 5 or fewer years, though this rate is highest among genetic counselors, at $79 \%(p<0.001)$. Genetic counselor respondents 
were significantly more likely to be female (93\%) than geneticist $(61 \%)$ or pediatric neurologist respondents $(48 \%)(p<0.001)$.

\begin{tabular}{|c|c|c|c|c|}
\hline & $\begin{array}{r}\text { Genetic Counselor } \\
\mathrm{n}(\%)\end{array}$ & $\begin{array}{r}\text { Geneticist } \\
\mathrm{n}(\%) \\
\end{array}$ & $\begin{array}{r}\text { Neurologist } \\
\mathrm{n}(\%) \\
\end{array}$ & $\begin{array}{l}\text { Total } \\
\mathrm{n}(\%)\end{array}$ \\
\hline \multicolumn{5}{|l|}{ Sex } \\
\hline Male & $7(7)$ & $12(36)$ & $52(51)$ & $71(31)$ \\
\hline Female & $87(93)$ & $20(61)$ & $49(48)$ & $156(68)$ \\
\hline Other & $0(0)$ & $1(3)$ & $1(1)$ & $2(1)$ \\
\hline \multicolumn{5}{|l|}{ Age } \\
\hline $22-25$ & $20(22)$ & $0(0)$ & $0(0)$ & $20(9)$ \\
\hline $26-30$ & $42(45)$ & $0(0)$ & $2(2)$ & $44(20)$ \\
\hline $31-40$ & $22(24)$ & $11(34)$ & $44(44)$ & 77 (34) \\
\hline $41-50$ & $4(4)$ & $10(31)$ & $28(28)$ & $42(19)$ \\
\hline $51-60$ & $4(4)$ & $6(19)$ & $12(12)$ & $22(10)$ \\
\hline$>60$ & $1(1)$ & $5(16)$ & $14(14)$ & $20(9)$ \\
\hline \multicolumn{5}{|l|}{ Years Working in Specialty } \\
\hline$<1$ & $13(14)$ & $1(3)$ & $2(2)$ & $16(7)$ \\
\hline $1-5$ & $60(65)$ & 6 (19) & $33(33)$ & $99(44)$ \\
\hline $6-10$ & $10(11)$ & $8(25)$ & $25(25)$ & 43 (19) \\
\hline $11-20$ & $6(6)$ & $8(25)$ & $18(18)$ & $32(14)$ \\
\hline $21-30$ & $3(3)$ & $5(16)$ & $11(11)$ & $19(8)$ \\
\hline$>30$ & $1(1)$ & $4(13)$ & $12(12)$ & $17(8)$ \\
\hline \multicolumn{5}{|l|}{ Active Patients at Practice } \\
\hline$<200$ & $10(11)$ & $3(9)$ & $1(1)$ & $14(6)$ \\
\hline $201-500$ & $15(16)$ & $4(13)$ & $18(18)$ & $37(16)$ \\
\hline $501-1000$ & $14(15)$ & $5(16)$ & $17(17)$ & $36(16)$ \\
\hline $1001-3000$ & $11(12)$ & $8(25)$ & $20(20)$ & 39 (17) \\
\hline$>3000$ & $10(11)$ & $7(22)$ & $28(28)$ & $45(20)$ \\
\hline Not Sure & $33(35)$ & $6(19)$ & $17(17)$ & $56(25)$ \\
\hline \multicolumn{5}{|l|}{ Patient Insurance } \\
\hline Predominantly Private & $25(27)$ & $3(10)$ & $20(21)$ & $48(22)$ \\
\hline Predominantly Medicaid & $31(34)$ & $15(48)$ & $40(42)$ & $86(39)$ \\
\hline Predominantly Military & $2(2)$ & $0(0)$ & $2(2)$ & $4(2)$ \\
\hline Mixed & $34(37)$ & $13(42)$ & $33(35)$ & $80(37)$ \\
\hline
\end{tabular}

Table 1: Demographic information of respondents 


\section{Genetic Test Ordering Practices}

When asked about genetic testing practices, there was no difference in the number of genetic tests ordered in the past month between genetic counselors (median: 12, IQR: 5-20) and geneticists (median: 12, IQR: 8-25). However, neurologists reported a significantly lower number of tests ordered (median: 6, IQR: 4-10; $p<0.001$ for both). The respondents were also asked about the types of genetic testing that they have ordered in the last six months. Neurologists were found to be significantly less likely to order whole exome sequencing $(p<0.001)$ compared to geneticists or genetic counselors. Genetic counselors are less likely to order or assist in ordering chromosome microarray than the other respondents $(p=<0.001)$.

\section{Testing Strategies for Common Neurological Conditions}

Respondents selected the genetic test or tests they would order as first-tier testing for a patient with an isolated neurological condition (Table 2). Overall, genetic counselor and geneticist responses were not significantly different. However, many of the testing plans selected by the neurologists varied significantly from those chosen by the geneticists, genetic counselors, or both.

Autism with Intellectual Disability: Respondents were most likely to select CMA and FXS analysis for the first line of testing they would offer to a patient with this indication $(93 \%$ and $84 \%$, respectively). Only $2 \%$ of respondents overall selected that they would order no testing for this indication. Neurologists were significantly less likely to order Fragile $\mathrm{X}$ analysis than genetic counselors $(p=0.041)$, less likely to order whole exome sequencing than genetic 
counselors and geneticists $(p=0.002)$, but more likely to order a karyotype for this indication $(p=0.020)$. Most respondents $(71 \%)$ included both tests currently recommended for first-tier testing, chromosome microarray and Fragile $X$ analysis. Forty-eight percent of all respondents selected only these two tests. Of the respondents who selected CMA and Fragile X analysis for a patient with ASD and intellectual disability, $13.5 \%$ also reported that they would also order whole exome sequencing as a first line test for this patient. Within that same group, $22 \%$ reported they would order a karyotype in addition to a CMA and Fragile $\mathrm{X}$ analysis ( $12 \%$ of genetic counselors, $12 \%$ of geneticists, and $27 \%$ of neurologists overall).

Autism without Intellectual Disability (isolated ASD): CMA and Fragile $\mathrm{X}$ analysis were the most selected tests for this indication ( $73 \%$ and $51 \%$ respectively). Overall, $17 \%$ of respondents indicated that they are unsure of what testing to order, or their decision depends on additional information. Twenty-six percent of neurologists responded that they would not order any testing for isolated ASD, significantly more than genetic counselors or geneticists $(p<0.001)$. Forty-nine percent of respondents included both chromosome microarray and Fragile $X$ analysis when testing a patient with isolated ASD, and 33\% selected those two tests exclusively.

Intellectual Disability: CMA and Fragile $\mathrm{X}$ analysis were again the most selected tests for intellectual disability ( $88 \%$ and $60 \%$, respectively). Sixteen percent of respondents reported that they did not know what testing they would choose, or that the decision would depend on additional information. In this case, neurologists were more likely to select that they would not order any testing $(p=0.046)$, and less likely to choose CMA $(p=0.001)$, Fragile $X$ analysis 
$(p=0.007)$, or whole exome sequencing $(p<0.001)$ for patients with intellectual disability. The respondents were most likely to select a combination of Fragile $\mathrm{X}$ and CMA when presented with a patient with isolated intellectual disability (29.1\%).

Epilepsy: The tests most likely to be selected to evaluate epilepsy were panel gene sequencing for related genes and CMA ( $63 \%$ and $41 \%$, respectively). Approximately $28 \%$ of respondents reported that they were unsure of the testing they would order or would require more information. Neurologists were significantly more likely to report that they are unsure/require more information $(p<0.001)$. Neurologists were less likely to order a CMA $(p<0.001)$ or whole exome sequencing $(p=0.002)$ than other respondents. For patients presenting with epilepsy, respondents were most likely to select panel testing alone (27.1\%) or panel testing with CMA (13.6\%) as their first-tier testing plan.

Behavioral Problems: The respondents were most likely to select that they would not order any genetic testing for this condition (49\%). The respondents who would order testing most commonly chose CMA (23\%) or Fragile $\mathrm{X}$ analysis (13\%). Neurologists were significantly more likely to select that they would order no testing $(p<0.001)$ and less likely to choose CMA $(p<0.001)$ or Fragile $X$ analysis $(p<0.001)$. 


\begin{tabular}{|c|c|c|c|c|}
\hline & $\begin{array}{l}\text { Genetic Counselor } \\
n(\%) \\
N=94\end{array}$ & $\begin{array}{l}\text { Geneticist } \\
n(\%) \\
N=33\end{array}$ & $\begin{array}{l}\text { Neurologist } \\
\mathrm{n}(\%) \\
\mathrm{N}=103\end{array}$ & 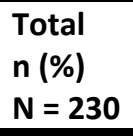 \\
\hline \multicolumn{5}{|l|}{ Autism with intellectual disability } \\
\hline I would not order any testing & $1(1)$ & $0(0)$ & $4(4)$ & $5(2)$ \\
\hline Chromosome microarray & $90(96)$ & $32(97)$ & $93(90)$ & $215(93)$ \\
\hline Fragile $X$ testing (FMR1 analysis) & $85(90)$ & $29(88)$ & $80(78)$ & $194(84)$ \\
\hline Whole exome sequencing & $19(20)$ & $6(18)$ & $4(4)+*$ & $29(13)$ \\
\hline Panel gene sequencing for related genes & $11(12)$ & $2(6)$ & $9(9)$ & $22(10)$ \\
\hline Single gene sequencing & $1(1)$ & $1(3)$ & $0(0)$ & $2(1)$ \\
\hline $\begin{array}{l}\text { Karyotype/Chromosome analysis } \\
\text { I don't know/it depends on other } \\
\text { information }\end{array}$ & $12(13)$ & $4(12)$ & $\begin{array}{l}28(27)+* \\
11(11)\end{array}$ & $\begin{array}{l}44(19) \\
24(10)\end{array}$ \\
\hline \multicolumn{5}{|l|}{ Autism without intellectual disability } \\
\hline I would not order any testing & $6(6)$ & $1(3)$ & $27(26)+*$ & $34(15)$ \\
\hline Chromosome microarray & $78(83)$ & $30(91)$ & $59(57)+*$ & $167(73)$ \\
\hline Fragile $X$ testing (FMR1 analysis) & $61(65)$ & $18(55)$ & $39(38)+*$ & $118(51)$ \\
\hline Whole exome sequencing & $9(10)$ & $1(3)$ & $2(2)$ & $12(5)$ \\
\hline Panel gene sequencing for related genes & $6(6)$ & $2(6)$ & $2(2)$ & $10(4)$ \\
\hline Single gene sequencing & $1(1)$ & $1(3)$ & $1(1)$ & $3(1)$ \\
\hline $\begin{array}{l}\text { Karyotype/Chromosome analysis } \\
\text { I don't know/it depends on other } \\
\text { information }\end{array}$ & $19(20)$ & $4(12)$ & $18(17)$ & $22(10)$ \\
\hline \multicolumn{5}{|l|}{ Epilepsy** } \\
\hline I would not order any testing & $2(2)$ & $0(0)$ & $6(6)+*$ & $8(3)$ \\
\hline Chromosome microarray & $52(56)$ & $18(55)$ & $24(24)+*$ & $94(41)$ \\
\hline Fragile $X$ testing (FMR1 analysis) & $5(5)$ & $3(9)$ & $1(1)$ & $9(4)$ \\
\hline Whole exome sequencing & $16(17)$ & $8(24)$ & $4(4)+*$ & $28(12)$ \\
\hline Panel gene sequencing for related genes & $67(72)$ & $19(58)$ & $56(55)$ & $142(62)$ \\
\hline Single gene sequencing & $2(2)$ & $0(0)$ & $4(4)$ & $6(3)$ \\
\hline $\begin{array}{l}\text { Karyotype/Chromosome analysis } \\
\text { I don't know/it depends on other }\end{array}$ & $6(6)$ & $1(3)$ & $1(1)$ & $8(3)$ \\
\hline information & $18(19)$ & $3(9)$ & $42(41) \dagger^{*}$ & $63(27)$ \\
\hline
\end{tabular}




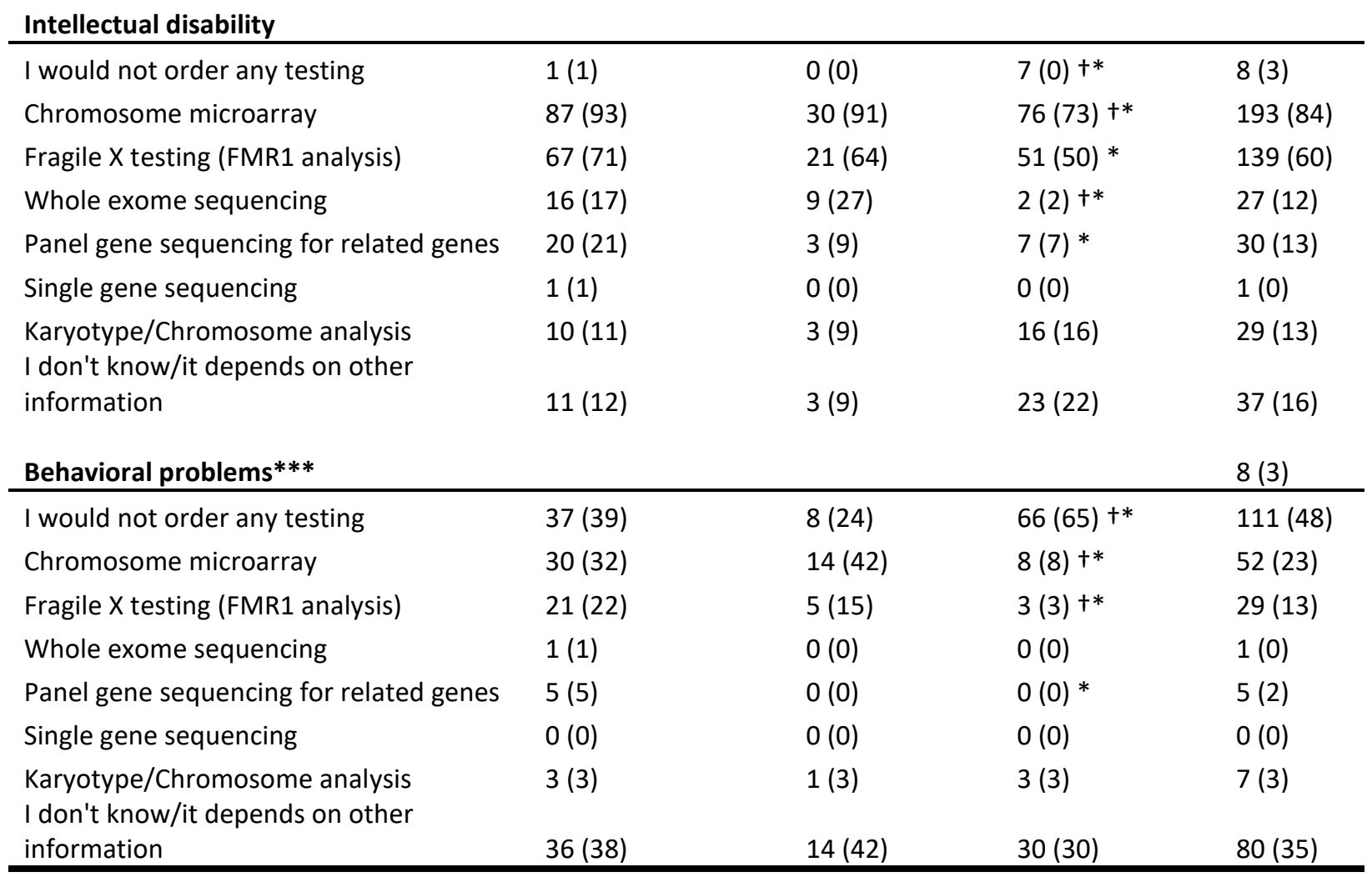

* denotes a statistically significant difference compared to Genetic Counselor response $(p \leq 0.05)$

+ denotes a statistically significant difference compared to Geneticist response $(p \leq 0.05)$

** Genetic counselor N = 93, Neurologist N $=102$

$* * *$ Neurologist $\mathrm{N}=101$

Table 2: First-line genetic tests selected for isolated neurological conditions.

\section{Perceived Knowledge Assessment}

Respondents rated their knowledge of topics related to neurogenetics (Table 3).

Neurologists rated themselves significantly lower than geneticists for knowledge of molecular

genetics $(p<0.001)$ and testing guidelines for genetic neurological conditions $(p=0.007)$, but

ranked themselves highest for knowledge of genetic neurological conditions. 
When asked about their confidence on topics related to ordering genetic tests for patients, neurologists consistently reported the lowest levels of confidence. The statistical significance of these ratings (scaled from 1 to 5 , with 5 being the highest level of confidence), are described below in Table 3. Neurologists reported significantly lower confidence on most topics: knowing when to order genetic tests, choosing the most appropriate test for a patient, interpreting test results, explaining test results to patients, and ordering tests to maximize diagnostic power while minimizing cost ( $p<0.001$ for all). Neurologists were not significantly different from the other respondents with regard to their comfort handling the emotions that arise during a results disclosure. Notably, genetic counselors were less confident in knowing when to order genetic tests $(p=0.001)$ and choosing the most appropriate test for a patient $(p=0.013)$ compared to geneticists.

A majority of neurologists responded yes when asked if they believed they would significantly benefit from further training on topics related to genetic testing, such as knowing when to order genetic tests, choosing the most appropriate test for a patient, interpreting test results, explaining test results, handling emotions during a results disclosure, and ordering tests to maximize diagnostic power and minimize costs (Table 3). A majority of genetic counselors and geneticists responded no to these same questions. 


\begin{tabular}{|c|c|c|c|}
\hline & $\begin{array}{l}\text { Genetic Counselor } \\
\mathbf{N}=92\end{array}$ & $\begin{array}{l}\text { Geneticist } \\
\mathbf{N}=\mathbf{3 3}\end{array}$ & $\begin{array}{l}\text { Neurologist } \\
\mathbf{N}=100\end{array}$ \\
\hline \multicolumn{4}{|l|}{ Self-Reported Knowledge (VAS 1-10), mean (SD) } \\
\hline Molecular Genetics & $8.11(1.62)$ & $7.88(1.80)$ & $5.08(2.43)+*$ \\
\hline Neurological Genetic Conditions & $6.8(1.63)$ & $7.18(1.42)$ & $7.28(1.82) *$ \\
\hline $\begin{array}{l}\text { Testing Guidelines for Genetic Neurological } \\
\text { Conditions }\end{array}$ & $6.71(1.94)^{\dagger}$ & $7.69(1.71)^{*}$ & $6.51(1.94) \dagger$ \\
\hline \multicolumn{4}{|l|}{ Confidence in Ability (VAS 1-5), mean (SD) } \\
\hline Knowing when to order genetic tests & $4.23+(1.11)$ & $4.67(0.99)$ & $4.17(0.92)+$ \\
\hline Choosing the most appropriate test for a patient & $4.13(1.07) \dagger$ & $4.48(1.00)^{*}$ & $3.75(0.95))^{* *}$ \\
\hline Interpreting test results & $4.15(1.06)$ & $4.30(0.92)$ & $3.41(1.08)+*$ \\
\hline Explaining test results to patients & $4.49(1.03)$ & $4.45(1.00)$ & $3.79(1.02) \dagger^{*}$ \\
\hline Handling emotions during result disclosure & $4.22(1.04)$ & $4.24(1.12)$ & $3.94(1.17) *$ \\
\hline $\begin{array}{l}\text { Ordering tests to maximize diagnostic power and } \\
\text { minimize cost }\end{array}$ & $4.26(1.08)$ & $4.22(1.01)$ & $3.24(1.16) \dagger^{*}$ \\
\hline \multicolumn{4}{|l|}{$\begin{array}{l}\text { I would significantly benefit from more training } \\
\text { on..., n (\%) }\end{array}$} \\
\hline ...When to order genetic testing & $25(27)$ & $5(15)$ & $67(71) t^{*}$ \\
\hline ...How to interpret test results & $23(25)$ & $9(27)$ & $72(75)+*$ \\
\hline ...Counseling patients about genetic testing options & $11(12)$ & $5(15)$ & $64(67)+*$ \\
\hline ...Explaining genetic testing results to patients & $12(13)$ & $3(9)$ & $64(67) \dagger^{*}$ \\
\hline
\end{tabular}

* denotes a statistically significant difference compared to genetic counselor response $(p \leq 0.05)$

+ denotes a statistically significant difference compared to geneticist response $(p \leq 0.05)$

Table 3: Self-rated knowledge and confidence regarding topics related to genetic testing for neurological conditions 


\section{Discussion}

Neurological conditions such as ASD, intellectual disability, and epilepsy have a significant hereditary component that warrants genetic testing. This study was conducted to characterize the genetic testing processes and practices of pediatric neurologists, geneticists, and genetic counselors. These results show a lack of consistency between the clinicians ordering genetic testing for pediatric neurological conditions and also identify areas where further education and refinement of guidelines relevant to genetic testing for these conditions would be valuable.

There is significant variance in the testing strategies selected by the responding members of these three professions. For the majority of questions requiring the participants to select a testing plan for an isolated condition, genetic counselors' and geneticists' responses were not significantly different from each other but were significantly different from the neurologists' responses. Neurologists tended to be more likely to refrain from ordering testing, particularly for patients with isolated ASD or epilepsy. They are less likely to order Fragile X analysis for patients with ASD and/or intellectual disability and less likely to order chromosome microarrays or gene panels for patients with epilepsy. These differences in practice could mean that the genetic testing ordered for a patient is strongly influenced by whether their testing is ordered by a genetics specialist or a neurologist. In the case of autism, providers who are not ordering Fragile $\mathrm{X}$ for these patients are not providing a complete genetic evaluation, as outlined by current professional guidelines, including those published by the American College of Medical Genetics and Genomics (10). In addition, cases where providers are indicating that 
they would order testing that is not listed as a recommendation by a professional organization's guidelines may contribute to the over-ordering and improper use of genetic tests.

Current recommendations support ordering chromosome microarray and Fragile $\mathrm{X}$ analysis as first-tier tests for patients with ASD. Although a majority of respondents overall selected a testing plan in line with these recommendations, a significant number of respondents did not include one or both of those tests in their testing strategy. Currently, there are no professional guidelines for ordering genetic testing for patients with epilepsy published by the AAP, ACMG, or CNS. As a result, respondents were more likely to respond "I don't know/it depends on other information" when asked about the testing they would order for a patient with epilepsy. This data shows that genetic testing guidelines, where they exist, are being followed inconsistently both within and across specialties. Some of the providers selecting testing plans that differ from published guidelines may be acting upon new research about genetic testing for neurological conditions released after the guidelines were published $(15,16)$. Others may be referring to outdated information, such as those ordering karyotypes rather than chromosome microarray for patients with ASD or intellectual disability. Additionally, the inconsistencies observed in the testing strategies of respondents point to a need for updated, collaborative guidelines that are accessible to and agreed upon by pediatric neurologists, geneticists, and genetic counselors.

This study identified pediatric neurologists as candidates for further education and training in ordering genetic testing, reflecting similar findings previously observed in neurologists (17). Though pediatric neurologists have responsibilities that extend far beyond 
the scope of neurogenetics, the current trend towards increasing integration of genetics into other medical specialties suggests that ordering genetic testing and interpreting genetic testing results is a growing component of the medical management of patients being cared for by pediatric neurologists. The pediatric neurologists who participated in this study reported that they are receptive to and interested in further education about the proper clinical implementation of genetic testing and believe that genetic testing is currently underutilized in the field of neurology. For this reason, efforts to provide education about genetic testing to this population would likely be well-received. Inclusion of more genetic counselors in neurology clinics also may improve the utilization of genetic testing in these settings while limiting the amount of further training that neurologists require to feel comfortable ordering genetic testing for their patients. Genetic testing technology is rapidly evolving and many clinicians will not be aware of the latest advancements, particularly those whose primary specialty is not genetics. Genetic counselors in neurology clinics can stay apprised of guideline revisions and shift this responsibility away from neurologists.

This study was limited in its statistical power by the comparatively few participating medical geneticists. Unlike genetic counselors and neurologists, geneticists were not reachable by listserv and were instead contacted personally. Additionally, the survey relied on selfreported data, which may not be an accurate representation of the respondent's actual genetic testing practices or knowledge of topics related to genetics. The survey tool used was not validated. As such, there is potential for respondents to interpret questions differently than intended. 
Future research should investigate methods for improving proper utilization of genetic testing for pediatric neurology patients, including examining the feasibility of incorporating more genetic counselors into pediatric neurology clinics and improving adherence to genetic testing guidelines. Research that investigates the testing practices of these providers with their actual patients via chart review would also add value to the field of pediatric neurology.

In conclusion, this research shows inconsistencies in the testing ordered for common neurological conditions by neurologists, genetic counselors, and geneticists. Options exist to address this variation in practice, such as writing collaborative, updated guidelines addressing genetic testing for these conditions and incorporating genetic counselors and other genetics specialists into pediatric neurology clinics. 


\section{Appendix}

Section 1 (Inclusion/Exclusion)

1. Which of the following best describes your job title?
a. Neurologist
b. Genetic Counselor
c. Geneticist
d. Other

2. (If job selected is Neurologist) Do you primarily see patients under the age of 18 ?
a. Yes
b. No

3. Do you see patients with neurological conditions (including developmental delay, autism, seizures, etc.) at least once every month?
a. Yes
b. No

4. Are you board certified in your field?
a. Yes
b. No

\section{Section 2}

1. In the past 6 months, have you ordered/recommended genetic testing for a patient?
a. Yes
b. No
c. I don't know

2. In the past month, approximately how many genetic tests for neurological conditions have you ordered/recommended be ordered for your patients?

a. [Number entry]

3. For what percent of the patients you see is a genetic test ordered?

a. [Number entry - increments of 5]

4. Of the tests that you have ordered for your patients in the last 6 months, approximately what percent of them were ? Your answers should total 100.
a. WES [Number entry]
b. CMA [Number entry]
c. Gene panel sequencing test (e.g. Epilepsy Panel) [Number entry]
d. Methylation analysis (e.g. Angelman/Prader-Willi Methylation Testing) [Number entry]
e. Triplet repeat expansion test (e.g. Fragile X Analysis) [Number entry] 
f. Single gene sequencing test (e.g. SCN1A Sequencing) [Number entry]

g. Other genetic test [Number entry]

5. In the past 6 months, have you ordered/recommended a genetic test be ordered for the following conditions?
a. Muscular dystrophy
b. Neuropathy
c. Spinal muscular atrophy
d. Amyotrophic lateral sclerosis
e. Ataxia
f. Huntington Disease
g. Dystonia
h. Epilepsy
i. Other neurological disorders

6. (If job selected $=$ neurologist or geneticist) Do you have access to a genetic counselor for referrals?
a. Yes, we have one on our team
b. Yes, I have access to an external genetic counselor
c. No, I do not have access to a genetic counselor
d. I am not sure

7. In the past 6 months, approximately what percent of your new patients did you refer to genetic counseling?
a. $0-10 \%$
b. $11-20 \%$
c. $21-30 \%$
d. $31-40 \%$
e. $41 \%-50 \%$
f. $51 \%-60 \%$
g. $61 \%-70 \%$
h. $71 \%-80 \%$
i. $81 \%-90 \%$
j. $91 \%-100 \%$
k. I do not refer patients to genetic counseling because a genetic counselor regularly sees each patient at my practice by default

\section{Section 3}

8. Below is a list of factors that you may consider when deciding on the genetic testing that you will offer a patient. Please rank each of the factors according to how often you consider those factors. [Likert scale: often an important factor, sometimes an important 
factor, rarely an important factor, never an important factor. Also able to select "I am not sure how I weigh this factor"]
a. Turnaround time
b. Patient cost and/or insurance coverage
c. Ability to interpret results
d. Test validity
e. Detection rate for suspected condition
f. Likelihood of incidental findings
g. Your confidence in a particular pre-testing clinical diagnosis
h. Patient preference
i. Ease of ordering

9. Which of the following factors have you ever considered to be the most important consideration when deciding on the genetic testing you will offer a patient? [Select as many as apply]
a. Turnaround time
b. Patient cost and/or insurance coverage
c. Ability to interpret results
d. Test validity
e. Detection rate for suspected condition
f. Likelihood of incidental findings
g. Your confidence in a particular pre-testing clinical diagnosis
h. Patient preference
i. Ease of ordering

10. Matrix: What do you consider to be the most significant advantage of ordering a

\begin{tabular}{|c|c|c|c|c|c|c|c|c|c|c|}
\hline & 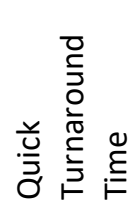 & 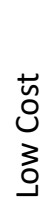 & 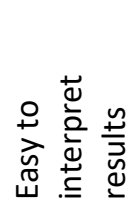 & 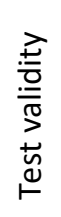 & 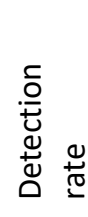 & 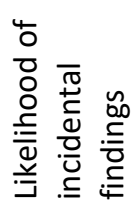 & 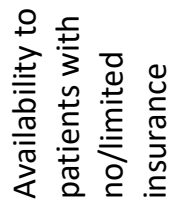 & 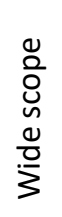 & 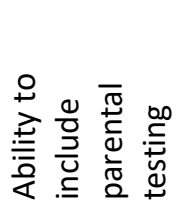 & $\begin{array}{l}3 \\
0 \\
\frac{0}{5} \\
\frac{1}{0} \\
0 \\
0 \\
0 \\
0\end{array}$ \\
\hline \multicolumn{11}{|l|}{ WES } \\
\hline \multicolumn{11}{|l|}{ CMA } \\
\hline \multicolumn{11}{|l|}{ Panel } \\
\hline Single Gene & & & & & & & & & & \\
\hline
\end{tabular}

11. Matrix: What do you consider to be the most significant disadvantage of ordering a ? 


\begin{tabular}{|c|c|c|c|c|c|c|c|c|c|}
\hline & 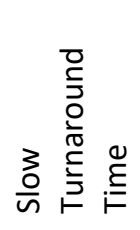 & 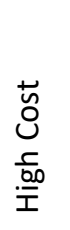 & 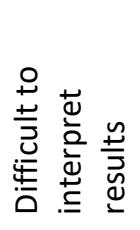 & 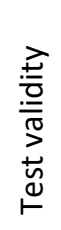 & 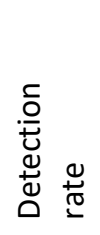 & 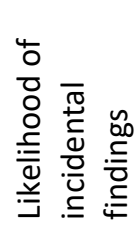 & 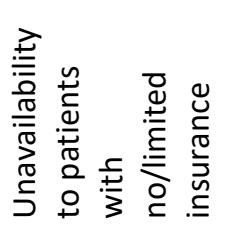 & 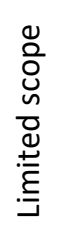 & $\begin{array}{l}3 \\
0 \\
\frac{1}{5} \\
0 \\
0 \\
0 \\
0 \\
0\end{array}$ \\
\hline \multicolumn{10}{|l|}{ WES } \\
\hline \multicolumn{10}{|l|}{ CMA } \\
\hline \multicolumn{10}{|l|}{ Panel } \\
\hline Single Gene & & & & & & & & & \\
\hline
\end{tabular}

Section 4

\begin{tabular}{|c|c|c|c|c|c|c|c|c|}
\hline & 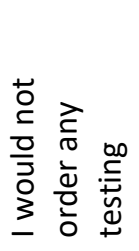 & $\sum_{U}^{\mathbb{S}}$ & 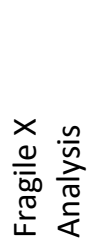 & 岁 & 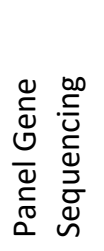 & 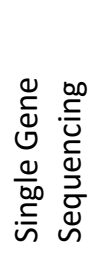 & 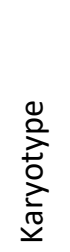 & 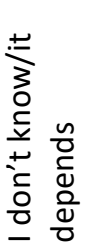 \\
\hline $\begin{array}{l}\text { Autism with } \\
\text { intellectual disability }\end{array}$ & & & & & & & & \\
\hline $\begin{array}{l}\text { Autism without } \\
\text { intellectual disability }\end{array}$ & & & & & & & & \\
\hline Seizures & & & & & & & & \\
\hline Intellectual Disability & & & & & & & & \\
\hline Behavioral Problems & & & & & & & & \\
\hline Epilepsy & & & & & & & & \\
\hline
\end{tabular}

12. Why did you choose the testing strategy that you did for Autism with Intellectual

Disability? (ex: follows professional recommendations, save cost to patient, likely to detect most common etiologies, took a guess, etc.) [Free response]

13. Why did you choose the testing strategy that you did for Autism without Intellectual Disability? [Free response]

14. Why did you choose the testing strategy that you did for seizures? [Free response]

Section 5

1. How would you rate your knowledge of...? (Likert Scale 1-10)

a. Molecular genetics 
b. Neurological genetic conditions

c. Genetic testing guidelines for neurological conditions

2. Do you believe you would significantly benefit from more training on? [Yes/No/Unsure]

a. When to order genetic testing

b. How to interpret results

c. Counseling patients about genetic testing options

d. Explaining genetic test results to patients

3. The following question will assess your confidence about various elements of ordering genetic tests. [Likert Scale: Very unconfident, somewhat unconfident, neither confident nor unconfident, somewhat confident, very confident]

a. Knowing when to order genetic tests

b. Choosing the most appropriate test for a patient

c. Interpreting test results, including variants of uncertain significance

d. Explaining genetic test results to patients in a manner that is scientifically accurate and patient-friendly

e. Handling the emotions that may arise during a genetic testing results disclosure

f. Ordering tests in a manner that maximizes the diagnostic power of my testing plan while minimizing cost

4. Do you believe that genetic testing is underutilized in the field of neurology in general?
a. Strongly underutilized
b. Somewhat underutilized
c. Utilized the right amount
d. Somewhat overutilized
e. Strongly overutilized
f. I'm not sure

Section 6 (Demographics)

1. What is your gender identity?
a. Man
b. Woman
c. Other

2. What is your age? [Text Entry]

3. How many years have you been working in your current specialty? Enter 0 if less than 1 year. [Text Entry]

4. In what state is your primary practice located? [Select state from dropdown menu]

5. What is the number of active patients at your practice?

a. Less than 200

b. 201-500 

c. $501-1000$
d. $1001-3000$
e. More than 3000
f. I'm not sure

6. Approximately what proportion of the patients you see are... [Number entry]
a. Privately insured
b. Insured by Medicaid
c. Insured by the military (ex: Tricare)
d. Uninsured/Self-pay

Thank you for participating in this survey. If you wish to be entered for a chance to win one of two \$50 Amazon gift cards, please follow the link and enter your email into the form. Your email will not be associated with your responses. [Link] 


\section{Bibliography}

1. Tchaconas, A., and A. Adesman. 2017. Diagnostic Evaluation of Children with Autism Spectrum Disorders: Clinician Compliance with Published Guidelines. Journal of developmental and behavioral pediatrics : JDBP 38: 29-38.

2. Cohen, D., N. Pichard, S. Tordjman, C. Baumann, L. Burglen, E. Excoffier, G. Lazar, P. Mazet, C. Pinquier, A. Verloes, and D. Heron. 2005. Specific genetic disorders and autism: clinical contribution towards their identification. Journal of autism and developmental disorders 35: 103-116.

3. DiGuiseppi, C., S. Hepburn, J. M. Davis, D. J. Fidler, S. Hartway, N. R. Lee, L. Miller, M. Ruttenber, and C. Robinson. 2010. Screening for autism spectrum disorders in children with Down syndrome: population prevalence and screening test characteristics. Journal of developmental and behavioral pediatrics : JDBP 31: 181-191.

4. Hall, S. S., A. A. Lightbody, and A. L. Reiss. 2008. Compulsive, self-injurious, and autistic behavior in children and adolescents with fragile X syndrome. American journal of mental retardation :

AJMR 113: 44-53.

5. Zecavati, N., and S. J. Spence. 2009. Neurometabolic disorders and dysfunction in autism spectrum disorders. Current neurology and neuroscience reports 9: 129-136.

6. Zack, M. M., and R. Kobau. 2017. National and State Estimates of the Numbers of Adults and Children with Active Epilepsy - United States, 2015. MMWR. Morbidity and mortality weekly report 66: 821-825.

7. Scheffer, I. E. 2011. Genetic testing in epilepsy: what should you be doing? Epilepsy currents 11: 107-111.

8. Kaufman, L., M. Ayub, and J. B. Vincent. 2010. The genetic basis of non-syndromic intellectual disability: a review. Journal of neurodevelopmental disorders 2: 182-209. 
9. Kidd, S. A., A. Lachiewicz, D. Barbouth, R. K. Blitz, C. Delahunty, D. McBrien, J. Visootsak, and E. Berry-Kravis. 2014. Fragile X syndrome: a review of associated medical problems. Pediatrics 134: 995-1005.

10. Schaefer, G. B., N. J. Mendelsohn, P. Professional, and C. Guidelines. 2013. Clinical genetics evaluation in identifying the etiology of autism spectrum disorders: 2013 guideline revisions. Genetics in medicine : official journal of the American College of Medical Genetics 15: 399-407.

11. Filipek, P. A., P. J. Accardo, S. Ashwal, G. T. Baranek, E. H. Cook, Jr., G. Dawson, B. Gordon, J. S. Gravel, C. P. Johnson, R. J. Kallen, S. E. Levy, N. J. Minshew, S. Ozonoff, B. M. Prizant, I. Rapin, S. J. Rogers, W. L. Stone, S. W. Teplin, R. F. Tuchman, and F. R. Volkmar. 2000. Practice parameter: screening and diagnosis of autism: report of the Quality Standards Subcommittee of the American Academy of Neurology and the Child Neurology Society. Neurology 55: 468-479.

12. Moeschler, J. B., M. Shevell, and G. Committee on. 2014. Comprehensive evaluation of the child with intellectual disability or global developmental delays. Pediatrics 134: e903-918.

13. Monaghan, K. G., E. Lyon, E. B. Spector, G. erican College of Medical, and Genomics. 2013. ACMG Standards and Guidelines for fragile $X$ testing: a revision to the disease-specific supplements to the Standards and Guidelines for Clinical Genetics Laboratories of the American College of Medical Genetics and Genomics. Genetics in medicine : official journal of the American College of Medical Genetics 15: 575-586.

14. Michelson, D. J., M. I. Shevell, E. H. Sherr, J. B. Moeschler, A. L. Gropman, and S. Ashwal. 2011. Evidence report: Genetic and metabolic testing on children with global developmental delay: report of the Quality Standards Subcommittee of the American Academy of Neurology and the Practice Committee of the Child Neurology Society. Neurology 77: 1629-1635. 
15. Rossi, M., D. El-Khechen, M. H. Black, K. D. Farwell Hagman, S. Tang, and Z. Powis. 2017. Outcomes of Diagnostic Exome Sequencing in Patients With Diagnosed or Suspected Autism Spectrum Disorders. Pediatric neurology 70: 34-43 e32.

16. Farwell, K. D., L. Shahmirzadi, D. El-Khechen, Z. Powis, E. C. Chao, B. Tippin Davis, R. M. Baxter, W. Zeng, C. Mroske, M. C. Parra, S. K. Gandomi, I. Lu, X. Li, H. Lu, H. M. Lu, D. Salvador, D. Ruble, M. Lao, S. Fischbach, J. Wen, S. Lee, A. Elliott, C. L. Dunlop, and S. Tang. 2015. Enhanced utility of family-centered diagnostic exome sequencing with inheritance model-based analysis: results from 500 unselected families with undiagnosed genetic conditions. Genetics in medicine : official journal of the American College of Medical Genetics 17: 578-586.

17. Salm, M., K. Abbate, P. Appelbaum, R. Ottman, W. Chung, K. Marder, C. S. Leu, R. Alcalay, J. Goldman, A. M. Curtis, C. Leech, K. J. Taber, and R. Klitzman. 2014. Use of genetic tests among neurologists and psychiatrists: knowledge, attitudes, behaviors, and needs for training. Journal of genetic counseling 23: 156-163. 
Sara Christine Wofford was born in Austin, Texas to Linda Jo Bagwell Wofford and William Tracy Wofford III. After graduating from Anderson High School, Austin, Texas in 2012, she entered The University of Texas at Austin and received the degree of Bachelor of Science with a major in biology in May, 2016. In August of 2016 she entered The University of Texas MD Anderson Cancer Center UTHealth Graduate School of Biomedical Sciences.

Permanent address:

3913 Walnut Clay Dr. Austin, Texas 78731 